\title{
Stage III Hypopharyngeal Carcinoma AJCC v6
}

National Cancer Institute

\section{Source}

National Cancer Institute. Stage III Hypopharyngeal Carcinoma A/CC v6. NCI Thesaurus.

Code C8040.

Stage III includes: (T3, N0, M0); (T1, N1, M0); (T2, N1, M0); (T3, N1, M0). T3: Tumor more than $4 \mathrm{~cm}$ in greatest dimension or with fixation of hemilarynx. N1: Metastasis in a single ipsilateral lymph node, $3 \mathrm{~cm}$ or less in greatest dimension. N2: Metastasis in a single ipsilateral lymph node, more than $3 \mathrm{~cm}$ but not more than $6 \mathrm{~cm}$ in greatest dimension, or in bilateral or contralateral lymph nodes, none more than $6 \mathrm{~cm}$ in greatest dimension. M0: No distant metastasis. (AJCC 6th ed.) 